\title{
Chapter 7 \\ A Tale of Three Villages: Contested Discourses of Place-Making in Central Philadelphia
}

\author{
Greg Niedt
}

\begin{abstract}
As the acceptance of queer identities has proceeded in fits and starts over the last few decades, the question has been raised, is it still necessary to have dedicated queer spaces? City dwellers often reason that with supposed improvements in safety and social mixing, the "gay ghettos" that form a transitional stage in neighborhood revitalization should now become common areas. Yet the capitalist logic that drives this thinking often trades the physical threat of exclusion or violence for an existential one, jeopardizing a distinctive culture that remains valuable in the self-realization process of local queer citizens. This is visible not only in changing demographics, but also in the production of discourse across multiple levels; language and semiotics help to constitute neighborhoods, but also to conceptualize them. This chapter examines how public signs and artifacts reify and sustain three competing narratives of a single central Philadelphia neighborhood in flux: the traditionally queer "Gayborhood" that developed shortly after World War II, the officially designated "Washington Square West," and the realtor-coined, recently gentrifying "Midtown Village." I argue that the naming and describing of these spaces, and how their associated discourses are reflected by their contents, continues to play a role in the ongoing struggle for queer acceptance. Combining observational data of multimodal public texts (storefronts, flyers, street signs, etc.) and critical discourse analysis within the linguistic/semiotic landscapes paradigm, I present a critique of the presumed inevitability of queer erasure here. This is supplemented with a comparison of grassroots, bottom-up, and official, top-down documents in various media (maps, brochures, websites, social media, etc.) that perpetuate the different discourses. Ultimately, a change in urban scenery and how a neighborhood is envisioned only masks the fact that spaces of queer expression, marked by their eroding distinctiveness rather than their deviance, are still needed.
\end{abstract}

Keywords Philadelphia • Queer identity • Gay neighborhoods • Pink economy • Gentrification

G. Niedt $(\bowtie)$

Liberal Arts, Pennsylvania Academy of the Fine Arts, Philadelphia, PA, USA

e-mail: gniedt@pobox.pafa.edu

(C) The Author(s) 2021

A. Bitterman and D. B. Hess (eds.), The Life and Afterlife of Gay Neighborhoods,

The Urban Book Series, https://doi.org/10.1007/978-3-030-66073-4_7 
Every year in early October, two street fairs take place in Center City Philadelphia, concentrated along the 13th Street corridor: Midtown Fall Festival and OutFest, the city's annual celebration of National Coming Out Day on October 11th. On occasion, they occur back to back on the same weekend, each drawing thousands of visitors, the Fall Festival on Saturday and OutFest on Sunday. Though they occupy the same geographic location, the goals of the organizers and nature of the events are quite different. Midtown Fall Festival is an outgrowth of the local business association and the many boutiques that have recently sprung up on 13th Street. OutFest, by contrast, arose from the queer community whose social and cultural life has been strongly visible in this part of the city for decades (Manley 2014). Depending on which day the visitor arrives, what will they perceive: a celebration of the commercial or of queerness? To the untrained eye, either of the two festivals might be seen as representative of the neighborhood, set against a backdrop of buildings and sensory media from which a number of discursive arrangements might be extracted.

The cityscape itself suggests who and what to expect within the borders of a neighborhood, their sensory and semiotic elements working together to indicate the "proper" occupants. As with other forms of media, when residents see themselves and their interests well-represented in the buildings, advertisements, objects, and bodies within the space, they will feel welcome, but within the blocks between Market and Pine, Broad and 11th Streets, there are multiple discourses of belonging operating simultaneously. The commonly used "Gayborhood" moniker is reflected in the rainbow signs and crosswalks, flyers and murals, and the display of queerness by individuals, especially in the evenings when patrons flock to the local nightclubs and bars. They announce their identity through dress, makeup, and movement, in ways that challenge heteronormative patterns of gendered interaction. Neutrally, the city's "Washington (Square) West" label (as the area lies west of Washington Square) appears in official signage, connected with other neighborhood names that line the municipal fabric of Philadelphia. And finally, "Midtown Village" appears in the promotional materials of the stores that constitute it, part of a cosmopolitan, "Globalese" (Jaworski 2015) register that echoes the area's gentrification. Implicit in that process is the erasure of queerness, putting the discourses into conflict.

In this chapter, I examine the case of this neighborhood in terms of how the different discourses that define it are put forward into the cityscape. I provide examples of semiotic texts that are representative of each of the three conceptualizations of the space, then discuss how they reflect the demographic, social, and economic changes occurring there. But from a broader perspective, what are the dynamics between the discourses themselves? Can they occupy the same coterminous space? Because their fundamental values are to some degree incommensurable-the reproductive logic of capitalism does not mix well with queer liberation, for examplethere is little room for compromise. The underlying tension becomes noticeable when observing how adherents of each perspective use discourse and the built environment itself to try and elevate their take on the neighborhood above the other two. 


\subsection{Background}

The meanings of a place are contested and contestable over time, as different groups attempt to center a given collection of streets, blocks, buildings, etc., on their own interests and history. Massey (1995) points out that place is a social construct, a locative idea that arises from the presence of, and repeated interactions between, the people who move within it. On the one hand, the efforts to define a place are grounded in a dynamic form of networked politics (Pierce et al. 2011) wherein both material realities of capital and the agency of individuals play a role. On the other, place is a discursive concept that is visibly manifest in the landscape, as different forms of architecture, artifacts, and bodies reinforce (or perhaps challenge) a person's notions of what "should" be there. As a blanket concept, urban gentrification provides a clear example of this duality: cycles of rising rents and taxes forcibly alter a neighborhood's demographic makeup, changing the visual semiotics of the cityscape and, in turn, how residents and visitors alike conceptualize it. The process is not an instantaneous one, and elements of a neighborhood's former character almost always peek through its current façade, providing a point of reference for what Massey calls the "feeling that there is or has been some kind of disruption between the past of these places and at least some elements of their present or their potential future" (Massey 1995: 183). Trinch and Snajdr (2017) meanwhile demonstrate that a familiarity with, and deployment of, the textual and visual indicators of previous landscape(s) can be translated into a kind of local cultural capital. After all, gentrification is partly cast as a struggle for a neighborhood's "authentic" self, and even those who profit from its socioeconomic changes recognize the benefit of calling forth the past. But Massey's use of the word disruption highlights the anger and bitterness that such change often engenders; as symbols of the different, often opposed, stages in a neighborhood's life, elements of the cityscape can summon these emotions forth, too.

Individual cases of gentrification are obviously rather different, but within the case of gay villages, a fairly regular pattern has been established. Marginalized by heteronormative society, queer folks move into "undesirable" neighborhoods, often sharing the space with others, e.g., artists, who depend on low rents, and in many cases displacing them (There is also a racial component to consider, as many white queers have in turn disrupted communities of color [Valentine 2002]). Over time, the cultural reputation of the neighborhood grows beyond its confines, attracting newcomers who see an opportunity for development; Philadelphia is no exception. It is important to remember that there has not been a concerted effort to expel queer individuals here, even though the economic realities have driven away many who do not fall into the white, cisgendered, male, affluent gay archetype (Those who do have not been directly marginalized, and many of them patronize bars, restaurants, and shops that are not overtly queer in character). But this shifting conception of the neighborhood poses a more existential threat. There is evidence that environments rich with examples of alternative sexuality are beneficial to the mental health of queer youth struggling to come to terms with who they are (Wienke et al. 2021); to 
erode that is to threaten the well-being of this population. Doan and Higgins (2011) describe queer spaces as a "Foucauldian heterotopia" of possibilities and liberatory politics, geographic vessels for the first internal, then performed, process of building an identity. They further situate the traditional narrative of gentrification in the more recent logic of branding. This is to say, heteronormative interests will appropriate queerness (along with other elements) to position themselves as "cosmopolitan," while ignoring and usually disenfranchising the actual people behind that label.

One common narrative casts queer spaces as "ghettos" not worth defending, since they keep heterosexuals from meeting and forming positive social ties with queer individuals. But this confuses integration with assimilation. Ghaziani (2014) points out the cognitive dissonance in this kind of "post-gay thinking," wherein queerness becomes both obvious and invisible; same-sex couples are praised for marrying and raising children, yet also for not centering their public identity around the very characteristic that separates them. What this suggests is that queerness is only acceptable when it is suborned to straightness. The threat arises when the vocal queer population is displaced and scattered, creating what Ghaziani calls a cultural archipelago; despite many same-sex couples' success in leading heteronormative lives, he equally cites many anecdotes of residents forced out by middle- or upper-class straight gentrification. True gayborhoods where queer identities are celebrated become so-called gay-friendly spaces that merely tolerate them.

\subsection{The Space in Question}

Founded in the late seventeenth century on Lenape land, Philadelphia is one of the oldest large cities in the USA, playing a prominent role throughout the history of the nation. It is commonly known as a "city of neighborhoods," with over one hundred such spaces_-notable for a city with not much more than $100 \mathrm{mi}^{2}$ of builtup land area. The city's long history has contributed to the development of individual neighborhoods' firm borders and distinctive character. As a center for immigration throughout the nineteenth and twentieth centuries, it has a diverse demographic makeup, although there are the usual patterns of racial/ethnic and economic segregation that one sees in many US cities (Logan 2013). Within that context, the area considered within this chapter lies in one of the more recently affluent corners of Center City (the downtown district). After the economic hardships of the 1980s, revitalization projects transformed the neighborhood, pricing out poorer residentsmany of them Philadelphians of color - and marketing it as a destination for visitors. In particular, there have been concerted efforts to draw affluent queer visitors into the local "pink economy" by highlighting a history of tolerance (Ghaziani, 2021). However, Center City is no longer the sole hub of queer life in the city. An influx of mainstream culture is most noticeable along 13th Street, where new restaurants and jewelry boutiques crowd out the gay bars and adult stores. Yet the Gayborhood remains a recognizable name to all, and the rainbow street signs, among other semiotic markers, remind observers where they are. Interwoven with those two sets of 
indicators are the impersonal arrangements of the City's municipal maps and tourist infrastructure: directional signs to other neighborhoods and landmarks, bike tour paths, etc.

Any one of those discourses could be used to delimit the neighborhood, depending on the lens through which one was observing the cityscape. They are coterminous, and the signs of each fall off abruptly at the same borders, though the City's official markers are similar in form and function to their signage in nearby areas. Despite this, in key ways the discourses are at odds with each other, the tension between them playing out in the changeable landscape.

\subsubsection{Gayborhood}

The evolution of Center City, particularly the area bounded by Chestnut, Pine, Broad, and 11th Streets, as a queer space has been a long, organic process echoing that in other cities. Manley (2014) links its growth to several factors. First, in the early twentieth century, theatres and performance venues multiplied and spilled over into burlesque and drag shows in local bars, creating a culture where the blurring of gender roles was more acceptable. Second, after Prohibition, many bootleggers became bar owners while maintaining their links with organized crime. They also understood that an establishment with (still criminalized) queer patrons would be less likely to call on the police. Skiba (2014) further elaborates the development of the area's tawdry reputation thanks to its growing role as a red-light district; the post-Stonewall opening of local bathhouses exacerbated this perception. And while Philadelphia's social mores were not libertine enough for an open queer culture until the liberation movement of the 1960s, the city's carnivalesque Mummers' Parade had since 1901 provided a liminal space for men, at least, to acceptably explore alternative gender practices (Dubin 1996; Leighton 2012). To the last point, the irony is that historically, the majority of the parade's participants have been cisgendered, heterosexual, white, working-class men-an intersection of identities commonly assumed to be homophobic.

Importantly, there is disagreement among researchers about when the neighborhood transitioned from being a place for socialization to a residential area. Stein (2004) shows that as the central district became whiter and younger with lower marriage rates, the concentration of queer residents was a natural consequence, while Manley argues that the change was driven by convenient proximity to the bars and cruising areas. In the early 90s, the term "Gayborhood" firmly replaced "gay ghetto" (Skiba 2014), with its implications of an active, dynamic community rather than one existing at the margins. By the time I began going out in the city as a young adult, the name was in common parlance, and semiotic moments discursively indicating that this is a queer space were highly visible in the landscape. The more enduring ones remain: posters at the gay bars, the purple newspaper boxes of Philly Gay News, rainbow street signs, etc., as seen in Fig. 7.1. While other areas of the city have gained their own reputations for alternative expressions of queerness (counterpoints 

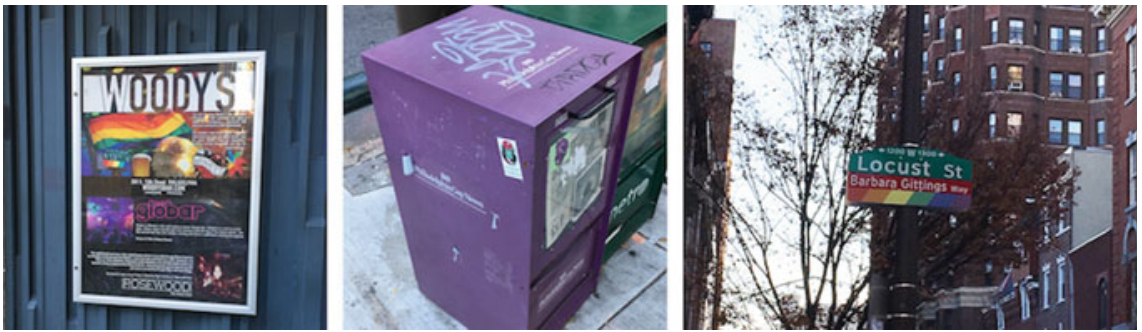

Fig. 7.1 Fixtures around the Gayborhood (Source Images by author)

to Center City's ever-rising cost of housing and predominantly white, cisgendered population), the central location of the Gayborhood and its institutions has arguably allowed it to maintain its predominance.

\subsubsection{Washington Square West}

Beyond the boundaries of the Gayborhood "proper," Washington Square West extends from Washington Square at 7th Street to Broad Street, between Market and South Streets (See Fig. 7.2). The name reflects the city's supposed role as a neutral arbiter of space, relying solely on geographical cues to define its districts. It turns up as the proper name for the area on Google Maps (albeit with slightly different boundaries). Kromer (2000) describes how this residential area was intended to have many of the same cityscape embellishments as its ritzy neighbor Society Hill (a.k.a., Washington Square East): brick paving, streetlamps, green space, etc. However, postwar federal funding ran out before the City could attend to these blocks, opening the path for private investment and purchase of abandoned properties. Perhaps this stunted progress toward revitalization contributed to impressions of the neighborhood as seedy or rough around the edges, either improved or worsened (depending on one's view) by the increasingly visible queer population. Regardless, property values have continued to increase under the auspices of the Washington Square West Historic District, the Washington Square West Civic Association, and other groups with vested interest in the area's success.

Mostly, it seems to be realtors who are interested in using the Washington Square West moniker (often abbreviated to Washington West or even WashWest). Walking through this space, one is most likely to see the label on For Sale or For Rent signs, as well as on the City's directional signs, capped by a stylized portrait of George Washington as a sort of local logo. These subtle markers in the built environment are noticeable in passing, even among the more glaring evidence of the other two discourses operating in the neighborhood. Putting aside the question of whether an area's "official" name should be one that is divorced from its social and cultural life 


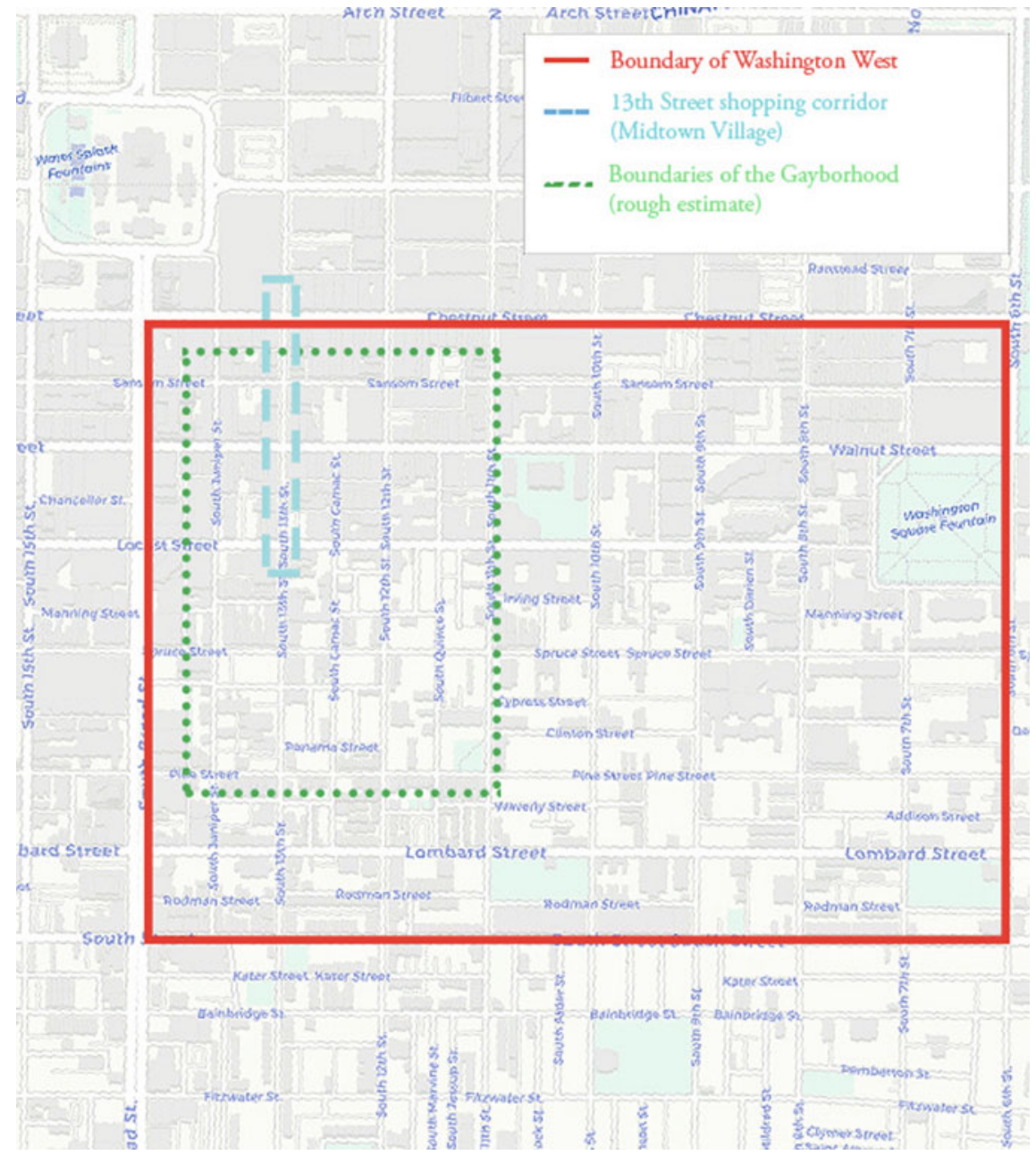

Fig. 7.2 Map of Washington Square West area (Source Image by author)

and history, it functions as a neutral reference point against which other possible constructions of the space can be compared. 


\subsubsection{Midtown Village}

In the wake of the 2007-2008 recession, the recently formed Midtown Village Merchants Association (MVMA) saw an opportunity to acquire and redevelop multiple properties in the neighborhood, an initiative spearheaded by developer Tony Goldman. The group's promotional materials refer to him as the "catalyst" for "recreating [the] neighborhood," saying that the merchants brought "renewed vitality after many years of decline" (MVMA 2018). While there has been no shortage of new businesses opening in the neighborhood, some of them owned and operated by queer individuals, they are noticeably different in contents, character, and clientele. The sex novelties shop Danny's, a fixture on 13th street for decades, now sits among quirky jewelry shops and upscale restaurants. Many nightlife spots that overtly catered to queer customers, bars like Woody's and Sisters, have been replaced and/or become spaces with a mixed crowd, to the consternation of long-time residents and visitors (Owens and Dent 2017; Spikol 2012). Perhaps because of this friction, the Midtown Village name has not widely caught on outside of the merchants' own use. Nevertheless, the social, cultural, and economic changes wrought by the expansion of this alternate commercial landscape reverberate beyond the few blocks of the 13th Street Corridor where the "Village" is focused.

Why is it problematic if Midtown Village merchants choose to deploy different semiotic tools to index another kind of identity, which attracts a new audience to their stores? The main issue is the newer arrivals' sense of entitlement to dictate the norms of the neighborhood. Owens (2019) recounts an encounter with a straight classmate in line at Voyeur (formally known as "Pure," a prescient name change) who asked if "this [is] where the fags go," seeing it as indicative of the heteronormative colonization of queer space. The overall acceptance of queerness in mainstream culture is used as an argument for allowing neighborhoods to become more mixed-but this doesn't entail that queer life should be remarkable within their borders (Ghaziani 2014). The introduction of heteronormativity means that those who follow it will also follow its precept that straightness is the default, and preferable to queerness. MVMA's website declares that its business owners are "open minded" without specifying how they enact that quality, nor mentioning the queer population at all. And while incidents like the one Owens reports are moments in time with personal repercussions, they punctuate the ongoing, low-level reminders in the materiality of the built landscape about the encroaching discourse's presence. Its associations with mainstream capitalism and majoritarian identity stand at odds with queer observers who are not affluent, cisgendered, and/or white, leading to conflicting ideas of what the neighborhood represents. 


\subsection{Discursive Moments}

The role of text and image in establishing the layers of affective geography is well-established in the literature, especially in the foundational texts of the linguistic/semiotic landscapes paradigm (See for example Blommaert 2007; Jaworski and Thurlow 2010; Scollon and Scollon 2003; Shohamy et al. 2010). The central idea of the discipline, which draws heavily from spatial production theories by Lefebvre, Tuan, and others, is that public texts that form a meaning-filled semioscape offer a glimpse into the sociolinguistic and discursive realities of an area. Each artifact gives visibility and adds weight to discourses about a neighborhood, block, intersection, or even smaller units of space. These accumulate into overall impressions about the character of this or that neighborhood. But it is not simply a numerical question of which discourse has the most signs; occupants who hold different ideologies and backgrounds will resonate to different degrees with the array of possible discourses available to unpack from a space. For example, the sex shop Danny's, with queer trappings regularly featured in its front window, can be perceived as either an integral part of the Gayborhood, a taxpaying business at an address located within the official Washington West district, or a lurid eyesore among the boutiques that make up Midtown Village. Meanwhile, the wine bar next door is simultaneously a symbol of unwanted gentrification, another taxpaying business, or a valued member of the growing commercial district. The signs that Scollon and Scollon (2003) refer to as transgressive with respect to a given discourse only become so in the ideological eye of a given beholder.

This chapter's purpose is not to determine whether conflict exists between residents from one side or another; mass media articles and social media are evidence enough of those opinions. Instead, I consider here a number of locations and artifacts from the neighborhood in terms of how they fit into the competing discourses. Like certain branches of geography, linguistic landscape researchers commonly employ photography, urban walking, and ethnographic observation to gather data, tools that function as part of a "place-making" process (Pink 2008). The examples presented here were documented during photo walks throughout the area; I attempted to capture a wide variety of signs and objects representative from each of the three discourses. There were hundreds of ready examples to photograph on each outing, but with the qualitative slant of the method, volume is less important than semiotic significance. I must also acknowledge that, as a queer resident of the city and a frequent visitor to the neighborhood in question, my own experience with the space forms a degree of bias that can only be acknowleged, not erased. 


\subsubsection{Snapshots from the Gayborhood}

The buildings and physical objects that signify the Gayborhood show a diversity built up over decades. Mainstream emblems, such as the use of rainbows, mix with the local to create a cityscape that signifies queerness in a number of ways, each requiring a different kind of familiarity with the visual language to recognize the text (Moriarty 2002). For example, the street scene at the top left in Fig. 7.3 shows one of the smaller, colonial-era side streets nestled in the neighborhood, lined with nineteenth-century houses and a bar flying a queered USA flag. The sign for Latimer Street shows one of the City's rainbow stripes designating the intersection as part of the Gayborhood, a convergence between the popular and "official" conceptions of the neighborhood. Compare these more universal markers with the mural in the top right, found on the site of the former 12th Street Gym less than a block away. The artwork depicts Gloria Casarez, the City's first director of LGBT Affairs and a leader in the local community, who passed away from cancer in 2014. While Philadelphia is also known as a city of murals, with thousands of them bedecking walls across the city, not many of them in the downtown area feature direct portraits of local, contemporary figures, especially women of color. The fact that the building in question was a popular gym for the gay community before its closure in early 2018 adds further weight for passerby who have the local knowledge to fully "read" the mural's significance.

The Gayborhood is also characterized by various types of ephemera that circulate in the space: the flyers and posters advertising drag shows and cabarets on the wall outside Franky Bradley's (a restaurant and bar that occupies the site of former lesbian bar, Sisters), books arranged in front of Giovanni's Room (now the oldest LGBT bookstore in the USA), the Bud Light banner aimed at a queer clientele outside the deli on 12th Street. Following McLuhan's famous dictum that the medium is the message, Scollon and Scollon (2003) emphasize the importance of multimodality in accounting for the meanings of various objects and how they are positioned in a spatial discourse. The mobility of these objects suggests, on the one hand, a kind of impermanence and fragility; they can easily be removed or blown away. On the other hand, such media add a sense of dynamism, change and growth to the landscape and are often the province of those who have less capital to express themselves through public signage. Ephemera reflect a more grassroots, performative, and adaptable ethos-qualities that have served residents of the Gayborhood well throughout the decades - but might cause a viewer to assign the discourse they represent less value.

Perhaps the temporary nature of these texts and artifacts in the landscape reflects another part of what Midtown Village merchants are referring to when they talk about the neighborhood's decline. The Gayborhood has always been flamboyant but not flashy, libertine but not (neo)liberal. And sexuality is undoubtedly part of the discourse's makeup, expressed through adult store signage, cheeky wordplay (such as Woody's, one of the most popular local bars), and signs like the Club Philly bathhouse logo in Fig. 7.2 (center right). Even though it is tucked away on another side street and the masculine silhouette only hints at the building's purpose, no 

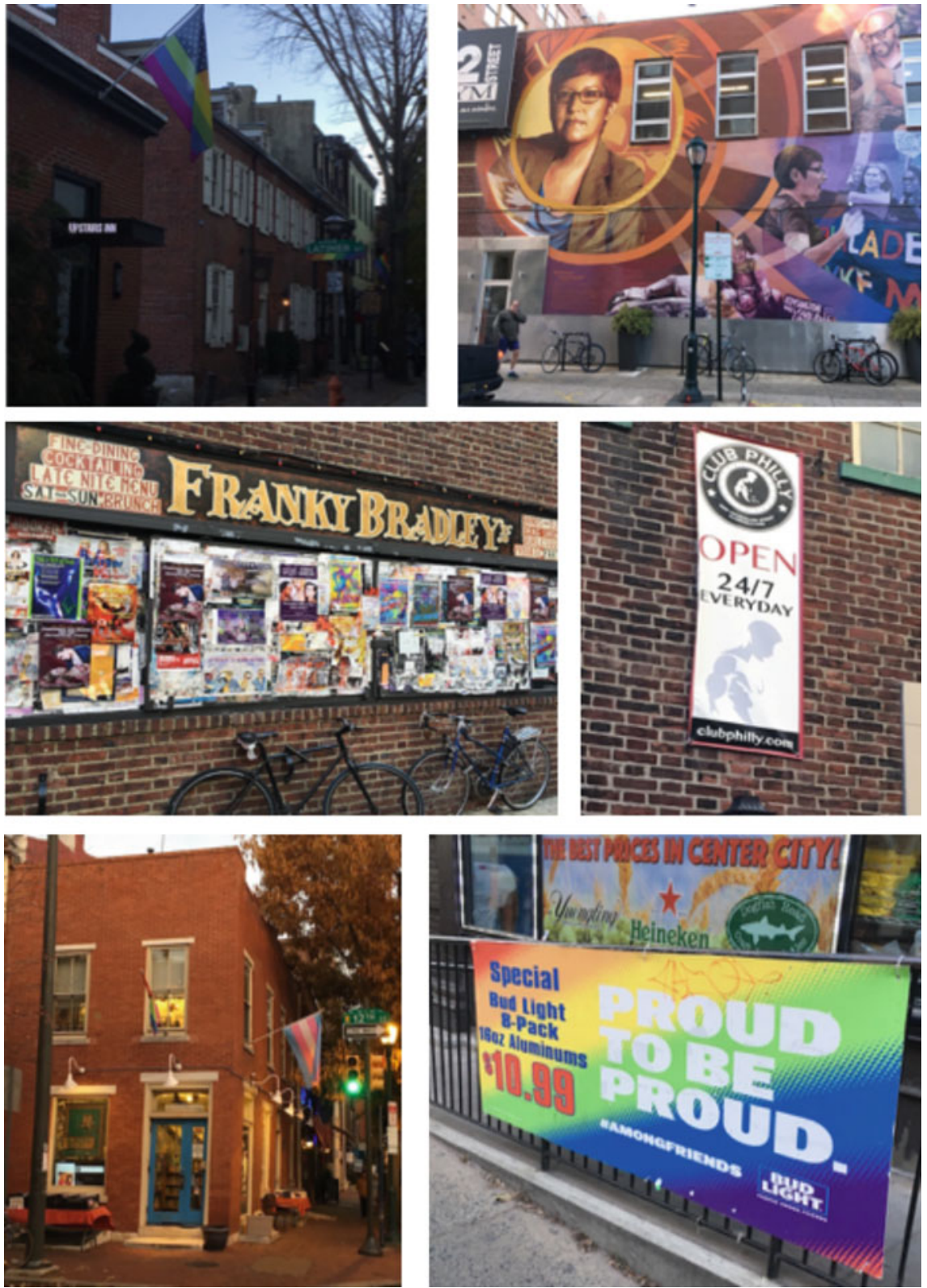

Fig. 7.3 Indicators of the Gayborhood discourse (Source Images by author) 
doubt even this display is too noticeable a reminder of the area's past for some of the more straitlaced new residents. Yet the discourse of sex is a necessary item of semiotic analysis in any landscape, queer or otherwise (Milani 2014), as it dictates attitudes toward occupants' presentation of bodies, their performance of gender, and their behavior toward each other. The Gayborhood has historically offered freedom from the confines of other, heteronormative interaction orders encountered almost everywhere else. To efface this aspect in the name of commerce or so-called decency would be a disservice to the generations of queer residents who wanted not to be forced to define themselves by how they were different.

\subsubsection{The Skeleton of Washington West}

So much of how the Washington West discourse is expressed relies on linkages with other neighborhoods-geographically, infrastructurally, semiotically. Scollon and Scollon (2003) categorize city signage as infrastructural when it alludes to the functional aspect of the city, which is perhaps the most significant portion of this discourse, exemplified by the signs in the top row of Fig. 7.4. The sign on the left directs passerby to locations both within and without the neighborhood, a mix of cultural sites and generalized commercial areas, while the one on the right provides a map with color-coded districts and distances to points of interest for cyclists. In neither case is the Gayborhood or Midtown Village alluded to, despite the presence of their semiotic markers near both signs; instead, on the left, the drawing of George Washington serves as an echo of the neighborhood's name and the city's historical role. Functional as it is, the sign still carries an allusion to the discourse in which it is emplaced.

Signs of this format can also be found throughout the surrounding neighborhoods, creating a recognizable visual language that indexes Philadelphia writ large, and positioning Washington West as part of that whole. These blocks become unique not because of any historical, cultural, or demographic distinction, but solely by their geographic differentiation. The materiality of the official signs is also worth noting, as the durability of signage can be read as an indicator of its provenance and authority, or at the very least of sufficient economic capital for a high production value. While there are also some signs in the Gayborhood discourse, and rather more in the Midtown Village discourse, that are crafted from metal, hard plastic, and other long-lasting materials, the Washington West discourse notably does not feature paper and cloth ephemera. Even objects created by ostensibly independent groups, such as the Mural Arts program that coordinates a great deal of tourism for Philadelphia's public art, or the Historical Society whose blue plaques are crafted from metal, have the literal weight of the city's backing. They cannot be torn down or easily defaced, and they are anchored to the landscape; compare this with the wall of flyers on the side of Franky Bradley's, or the rainbow flags that eventually tatter.

One could make the counterargument that signage such as that seen in the bottom row is durable and alludes to the queer heritage of the neighborhood; the rainbow 

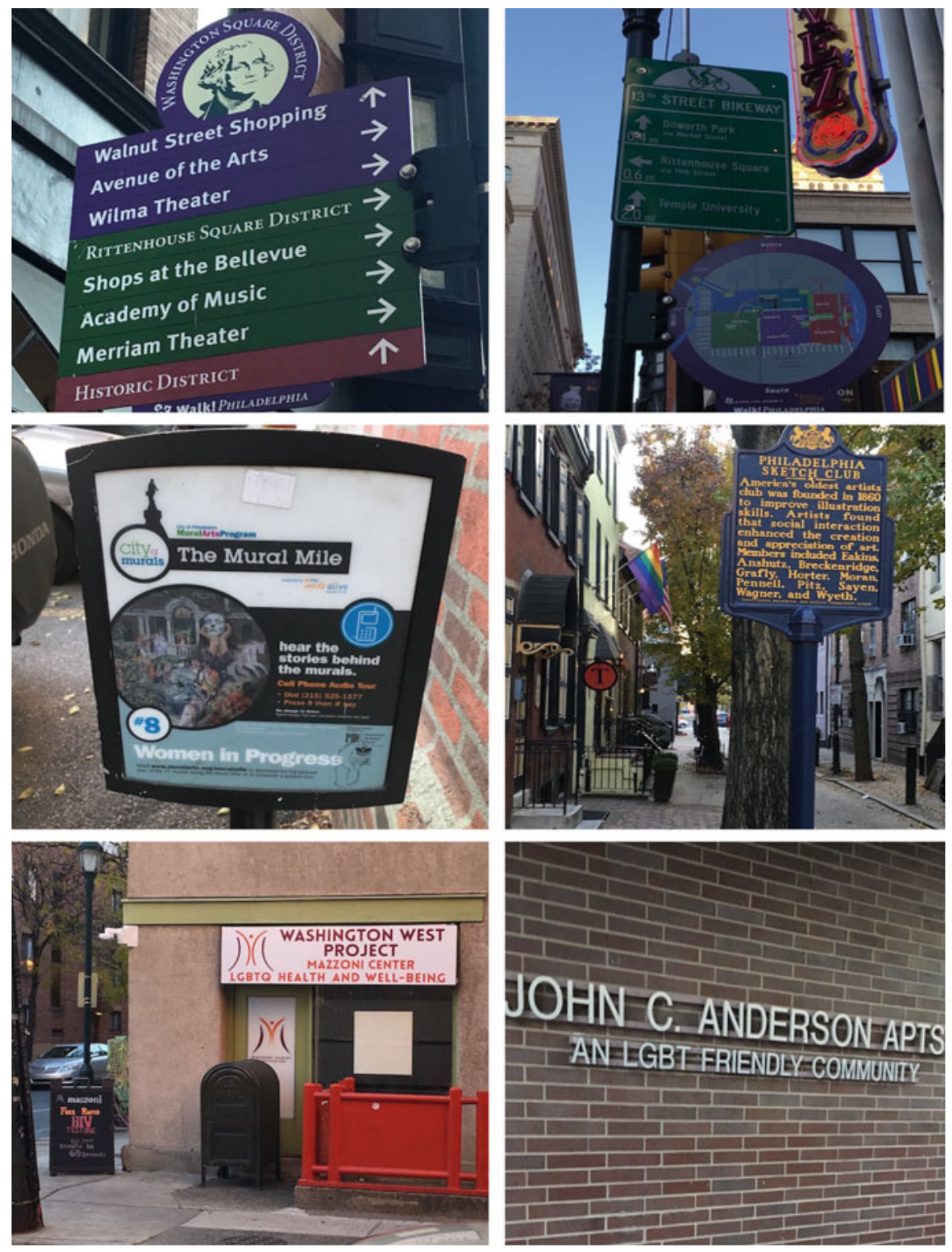

Fig. 7.4 Snapshots from Washington West (Source Images by author)

stripes on street signs are a further concession that could not have happened without City Hall's blessing. Yet subtle multimodal indicators in their construction and interpretation matter; "Washington West" is far more prominent on the health center sign than "LGBTQ" and the formal metal-on-brick apartment sign notes that the community is LGBT friendly. It isn't that these signals are unwelcome or especially 
problematic, but they are not exactly the active celebration of queer life characteristic of signage aligned with the Gayborhood. The photograph on the right of the middle row in Fig. 7.3 directly illustrates the disconnect between the two overlapping spatial discourses. Behind the historical marker for the location of the Philadelphia Sketch Club is a rainbow flag marking the entrance to Tavern on Camac, one of the oldest gay bars in the city; the Venture Inn, which survived nearly a hundred years until its closure in 2016, lay a bit farther down the street. Yet these do not qualify for historical recognition. Perhaps in time, there will be other historical markers that memorialize the queer past of the neighborhood, integrated into the sanctioned discourse of the city, but for now they remain separate, articulated by two different logics of expression.

\subsubsection{Welcome to Midtown Village}

Like the Washington West discourse, producers of signage that reflects the Midtown Village discourse make much ado about their open-mindedness. However, while the City has made tacit moves toward at least acknowledging the presence of queerness, there is little to back up the claim of tolerance by the merchants along 13th Street. The textual and visual semiotics of the corridor instead reflect the same preoccupations with cosmopolitanism and commerce that one sees in other gentrifying neighborhoods, both in Philadelphia and elsewhere.

The images in the top two rows in Fig. 7.5 are representative of what one sees in the storefronts along 13th Street and its immediate environs. On the shop wall in the top left, the "story" presented draws on conventions that index upscale shopping: vocabulary ("unique," "a true boutique experience," "we are passionate," etc.), the "established in (year)" marker of authenticity, an array of professionally designed fonts. Next to it, the display of an award for "Best Shopping Experience" in the city begs the question, according to whom? In the middle row, the jewelry store's name, Bella Turka, provides an example of the deployment of linguistic codes for their cosmopolitan meaning rather than their actual content (Curtin 2014). The Italianate name with its connotations of elevated culture is more important than its translation; other shops in the district also feature Italian names, as well as French and Japanese. And then there are connections to other trends, such as (in this case) the recently reawakened tiki bar craze sweeping the nation. Capitalist overtones of these semioscapes, bolstered by materiality - the fashion items in Lou Lou and Bella Turka's windows, the bombastic décor of Tiki-are in keeping with the primary reason for Midtown Village's existence: generating profit. But they also reflect broader trends in the country's consumer culture as it reflects patterns of gentrification. Trinch and Snajdr (2017) demonstrate the subtle affective impact of businesses that embrace these semiotic codes; they connote worldliness and aspirations of wealth, but lose their connection to the local. For the resident who can afford to live and/or shop on these increasingly expensive blocks, participation in the life of the neighborhood in accordance with the Midtown Village discourse requires 

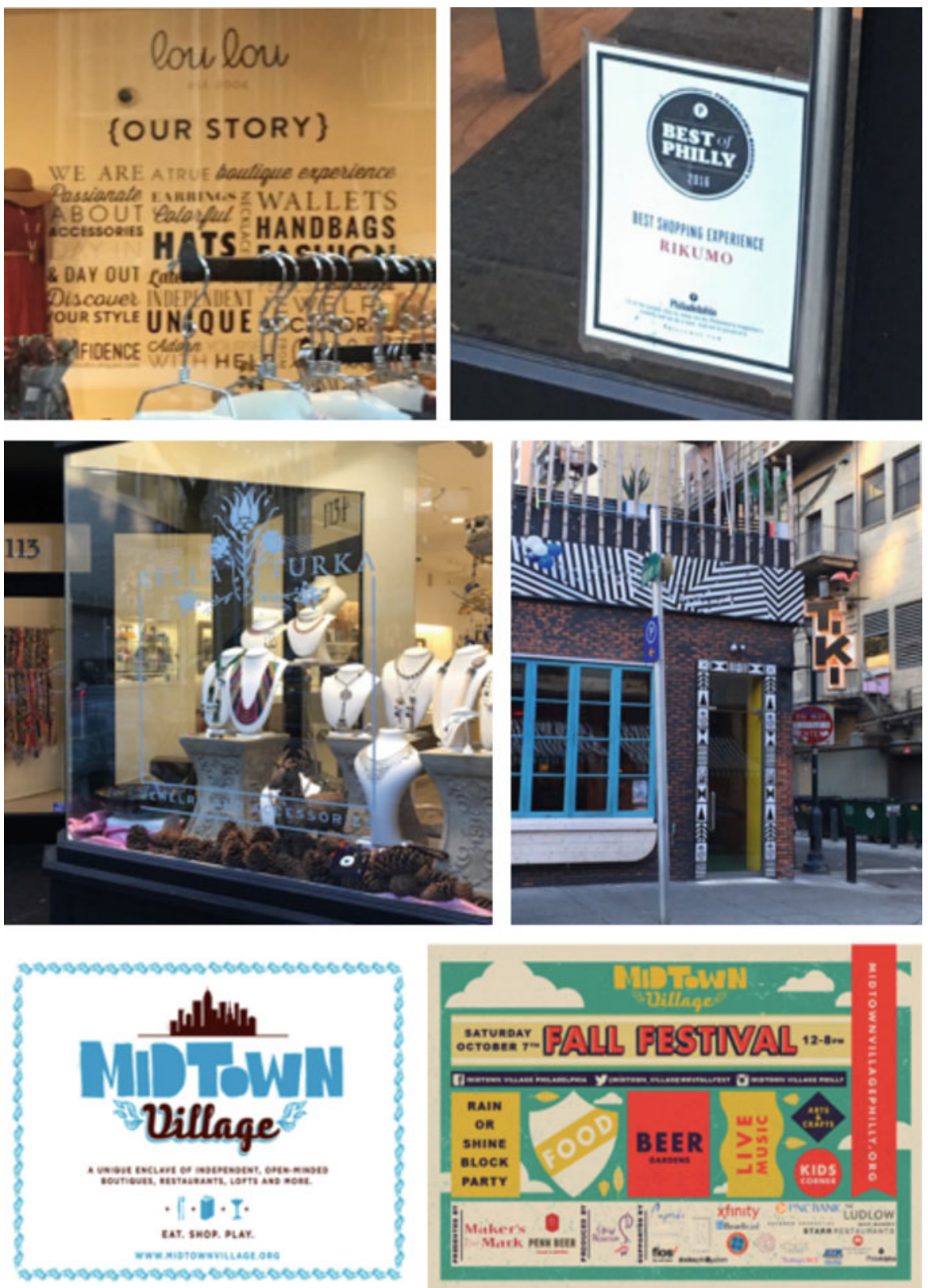

Fig. 7.5 Midtown village moments (Source Images by author) 
being a homo economicus, contributing to circuits of capital. Implicitly, if one isn't shopping, dining out, or otherwise purchasing some kind of experience at a premium, then what are they doing there?

Images from the business association's website drive this point home. On the left of the bottom row in Fig. 7.4 is an official placard declaring that Midtown Village is a "unique enclave of independent, open-minded boutiques, restaurants, and more." Leaving aside the question of what makes them unique, the word enclave implies that they are surrounded by a city that is not independent or open-minded, that they stand alone in a gritty wilderness. In one sense, the merchants assessment of difference rings true: on nearby blocks, there is homelessness, drug use, and other issues that city downtowns often face. By closing themselves off from their surroundings rather than growing organically from the neighborhood, they do not solve any problems, but instead exacerbate the rising cost of living. The fall festival flyer on the bottom right aligns the Village with corporate sponsorship and heteronormative values (a "Kids Corner") that stand in contrast to the largely self-constructed community of the Gayborhood. Extending Edelman's (2004) proposition that queer individuals have "no future" (in straight terms) because there is no imperative to have children and accumulate for them, they are further shut out if they are not able or willing to participate in the logic of these spaces. Or perhaps the open-mindedness touted by these boutiques certainly extends to queer individuals-but only to those who can afford to be there, and who fit the mold of straight expectations.

The underlying problem with "re-vitalization" in any context is its semantic implication that what came before was broken, low-quality, or unappealing, even when there is evidence to the contrary. Discursively, the shopkeepers who espouse the Midtown Village name and ethos have to rely on this narrative in order to justify their presence and the erasure of the neighborhood's previous character. An example: one business on 13th Street distributes postcards telling their story, saying that they "helped transform the once-desolate neighborhood into trendy Midtown Village." While I was not present for the urban decay of the 1980s, I can vividly recall the early 2000s in this part of Center City, when there was plenty of activity along the 13th Street corridor associated with queer spaces. But the desolation referred to in this piece of media is relative; certainly, in my adolescence, there was a dearth of the kind of fashion boutiques and expensive restaurants that one is liable to find now. Lurking under the surface is the idea that this lack stands in opposition to trendiness, and trendiness is beneficial for the neighborhood. In fact, it is beneficial for the owners of successful brick-and-mortar stores who market themselves to visitors, and perhaps for the visitors themselves who want another location to shop. It is beneficial for homeowners who are financially stable enough to afford the increase in taxes and reap the rewards of higher property values. Yet there isn't much overlap between these groups and a queer community that is more concerned with socialization and the development of identity than with accruing material wealth.

When it comes to the semiotic landscape, there is one moment that stands out to me as indicative of the neighborhood's dynamics and the manifestation of tension between these three discourses. At the intersection of 13th and Locust streets, the epicenter of the club scene in the Gayborhood-there are a dozen bars focused on a 
queer clientele within a two-block radius - the City painted rainbow crosswalks on the asphalt in 2015. A reflection of the stripes underneath street signs in the area, the gesture served as an official acknowledgment of the local demography, even as queer folks were being priced out of the area: an alignment between Washington West and the Gayborhood. However, in subsequent years, the crosswalks faded into dull, chipped paint, crisscrossed with utility workers' marks and riddled with tire tracks, becoming more a symbol of decay than lasting support from the City (Boren 2018; see also Fig. 7.6).

Although one enterprising local individual took it upon himself to freshen up the paint in time for Outfest 2019 (Shaw 2019), it is difficult not to interpret this erosion as a reminder of the City's priorities with regard to the communities in the area. The former inhabitants who gave it life have been, if not forgotten, then at least brushed off in favor of new, moneyed arrivals. While the latter group has no qualms about appropriating the cultural cachet of queerness to further their own goals, local businesses must adapt to the new economic realities or fade away. Returning to the example with which I opened this chapter, when the Midtown Village Festival was announced on social media this past autumn, this struggle was more directly on display. Once again deploying the language of globalized cosmopolitanism, the event's Facebook page stated that:

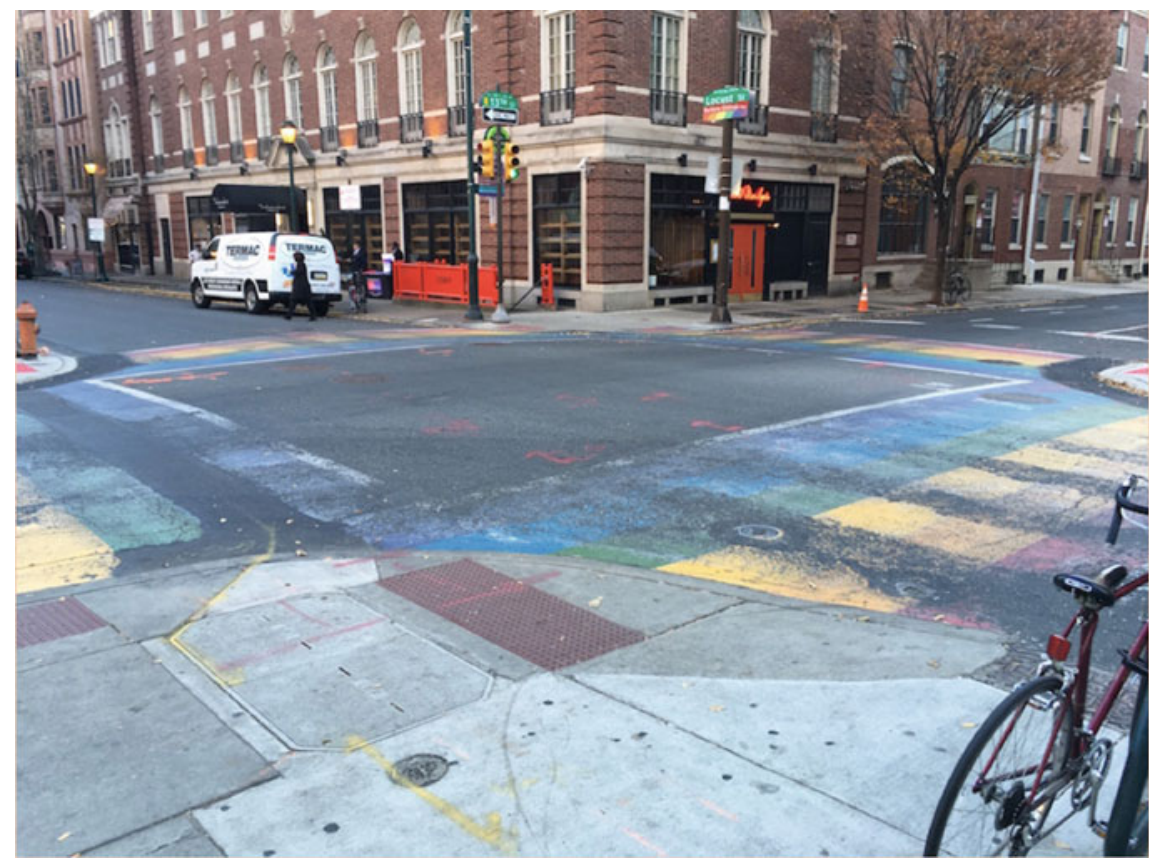

Fig. 7.6 13th and Locust, before the temporary touch-up work for Outfest 2019 (Source Image by author) 
Midtown Village has a collection of unique, independent, entrepreneurial, open-minded boutiques, restaurants, lofts, and much more. The Midtown Village Fall Festival attracts thousands of visitors in one day to experience a variety of activities including multiple stages of live entertainment, food and beverage sampling, merchant and vendor displays, crafters, children's activities, and much more!

The immediate response from several users included comments like, "WTH is a midtown village? The gayborhood has a fall festival? Cool" and, "That's the Gayborhood, not Midtown Village. Midtown Village is in Wilkes-Barre." Statements like these are a bit tongue-in-cheek, but still illustrate locals' sense that the Fall Festival and the business association that runs it represent a threat to the geodiscursive identity they are so familiar with. Note that once again, "open-minded" is the only possible allusion to queerness in the description of the festival, and the specific mention of "children's activities" serves as a subtle reminder of heteronormativity. The promotional materials associated with the festival also stand in stark contrast to that used for Outfest. The Fall Festival's visual media, presumably collected from previous years, showed crowds of mostly white, straight families and couples, drinking beer and browsing tables of wares; as shown in Fig. 7.5, they are also not shy about their corporate sponsorship. Outfest's photos, on the other hand, are populated by mostly young people with a variety of gender expressions, queer couples, people of different races and ethnicities, cheering and waving flags. The former is a demonstration of capital; the latter is a celebration of liberated sexuality (Not that Outfest doesn't also have vendors, but they are not the discursive focus of the event).

What is clear from these interactions is that the fight for the soul of the neighborhood is not yet over, as various interests attempt to have their discourse come out on top. Is it possible to have these competing ideas of the area coexist? Arguably, no: by its nature, the capitalism represented by Midtown Village must eventually swallow and assimilate all competition, while the queerness represented by the Gayborhood is theoretically defined by its resistance and refusal to capitulate to those norms. The two have hitherto managed to occupy the same space, with the moderating influence of the City - permits for events, structural boundaries, laws that have to be followed-somewhere in between. But as prices continue to rise, the significance of Center City as a primary nexus of queer socialization in Philadelphia will continue to erode, a process visible in the changing built environment and visual semiotics of the area. At some point, there must be a reckoning that will determine the identity of the neighborhood moving forward.

\subsection{Further Directions}

Dense urban areas often prove to be rich sources of data for research, such that it is impossible for any single paper to fully delve into all their aspects. This one should not be treated as anything but an opening of critical inquiry into the discourse of the Gayborhood, one which could lead to a number of other investigations. I list three possibilities here. 
First, many of the examples given in this paper reflect my personal experience with the shifting nature of the neighborhood and the anecdotes of friends and colleagues. While the local newspapers and online media give some more weight to the attitudes that I have encountered as a resident of the city, formal interviews could illuminate the emotional repercussions of the landscape's evolution. In linguistic landscape studies, pairing interviews with visual data (see for example Garvin 2010; Modan 2008) is a common method for moving from the quantitative counting of signs to the qualitative analysis of what they signify to individuals. In the case of the Gayborhood/Midtown Village, perhaps the best group to interview would be the business owners, to hear more about their intentions with respect to how they present themselves in the space. Interviews on the street, vox populi style, could also shed some light on the case; simply asking, "What is this neighborhood called?" while within its bounds might give some sense of how deeply each discourse has penetrated the Philadelphia psyche.

There are also points of connection with media, artifacts, landscapes, and other semiotic moments outside the boundaries of the zone discussed here. For example, do the City's official signs in other neighborhoods perform a similar discursive role? Another corridor that has been rapidly gentrifying is East Passyunk Avenue, a handful of blocks to the Gayborhood's south. As older Italian American occupants are priced out and new boutiques open along the length of the street, the same concerns have been raised as the City re-brands the area to reflect its changes. Along a different axis, how do the processes occurring in other cities, as indicated in this volume, reflect those taking place in Philadelphia? No two cities and no two neighborhoods will have the exact same struggle for the right to determine their "meanings," but parallels do arise. There is a kind of intertextuality —or perhaps interdiscursivity - that enables comparisons to be made and lessons to be learned from one case to another, allowing producers and consumers of the landscape alike to understand the semiotic codes at play. The "globalese" deployed by Midtown Village would have no effect if it did not recognizably encode wealth and status to those who read it. While I have provided several examples of media items and snapshots of the city in this chapter, there are countless others to discover, though any researcher must be careful not to exhaust a question beyond the point at which it has been answered.

Finally, examining a single moment in the evolution of the cityscape, even in the midst of an identity crisis for the neighborhood, is limited to a relatively static perspective. A more diachronic (and probably extended) study would account not only for how the Gayborhood reflects current ideologies, but also the past and likely futures. Beyond anecdotes like the one provided by Owens above, oral histories from long-term residents are useful for giving context to the historical development of a space. They add a personal dimension to the argument that having the freedom to develop one's minority identity is invaluable, and shed some light on how the evolution of a neighborhood impacts the evolution of attitudes toward the bodies that occupy it. Archival research can further reveal when the identities of spaces were determined, and how conversations around them unfolded over time. Again, one must consider scale: how did the local discourses about space, gender, and sexuality align or disalign with those at the regional or national level? And how have discourses of race, ethnicity, and class at different levels fit in? As a "majority minority" city with 
a liberal slant and a historically strong working class, these aspects are all highly relevant to the Philadelphia equation.

\subsection{Conclusion}

In this chapter, I have described and given examples of the three discourses circulating in the space traditionally ascribed to Philadelphia's Gayborhood. Each has its supporters and detractors, and all are visible in the neighborhood through the use of semiotic markers like signage, ephemera, and the construction of the cityscape. While they are predicated on historical and material realities of the city, these discourses are connected to other proximate ones, both geographically (elsewhere in Philadelphia) and conceptually (queer spaces in other cities). They help to produce localized identities and patterns of interaction, as well as affective ties among residents to the space itself, its meanings, and each other.

I close by stating that ideally, the presence of multiple discourses should not have to cause friction. As with other instances of gentrification, if new arrivals would respect the preexisting culture and population, this would mitigate (though not fully counteract) some of the social effects. The problem for the Gayborhood is when straight individuals invite themselves in with no interest in queerness beyond how it can benefit them and their own ways of being, insisting that they know what's best. Whether this stems from the idea that separate queer space is no longer necessary or a belief that capital is the cure for all ills, the upshot is that their approach is destined to ruffle feathers among residents who are more or less content with the way things are. The stability of a neighborhood depends in part on the comfort its members feel with the space where they live, work, play, meet, and celebrate. In order for the queer population of Center City to continue to feel at home, their struggle for recognition and acceptance over the past decades must not be overridden by those for whom it has no weight. And in the end, it is the responsibility of these new entrepreneurs to ensure that what they bring to the table does not diminish a community that has already fought to achieve so much.

\section{References}

Blommaert J (2007) Sociolinguistic scales. Intercult pragmat 4(1):1-19

Boren M (2018, July 18) Philadelphia's rainbow cross walks are falling apart: will anyone fix them? The Philadelphia Inquirer. Available via https://www.inquirer.com/philly/news/pennsylvania/phi ladelphia/philadelphia-rainbow-crosswalks-gayborhood-lgbt-repairs-20180718.html

Curtin M (2014) Mapping cosmopolitanisms in Taipei: toward a theorisation of cosmopolitanism in linguistic landscape research. Int J Sociol Lang 2014(228):153-177

Doan PL, Higgins H (2011) The demise of queer space? Resurgent gentrification and the assimilation of LGBT neighborhoods. J Plan Educ Res 31(1):6-25 
Dubin M (1996) South Philadelphia: mummers, memories, and the Melrose Diner. Temple University Press, Philadelphia, PA

Edelman L (2004) No future: queer theory and the death drive. Duke University Press, Durham, $\mathrm{NC}$

Garvin R (2010) Postmodern walking tour. In: Shohamy E, ben Rafael E, Barni M (eds) ELinguistic landscape in the city. Multilingual Matters, Clevedon, UK, pp 252-271

Ghaziani A (2014) There goes the gayborhood? Princeton University Press, Princeton, NJ

Ghaziani A (2021) Why gayborhoods matter: the street empirics of urban sexualities. In: Bitterman A, Hess DB (eds) The life and afterlife of gay neighborhoods: renaissance and resurgence. Springer, Dordrecht, Netherlands, pp 87-114

Jaworski A (2015) Globalese: a new visual-linguistic register. Soc Semiot 25(2):217-235

Jaworski A, Thurlow C (2010) Introducing semiotic landscapes. In: ibid. (eds) Semiotic landscapes: language, image, space. Continuum, London

Kromer J (2000) Neighborhood recovery: reinvestment policy for the new hometown. Rutgers University Press, New Brunswick, NJ

Leighton CE (2012) Real girl dances in mummer throng: a performative historiography of gender in the Philadelphia Mummers Parade. Text Perform Q 32(1):38-58

Logan JR (2013) The persistence of segregation in the 21 st century metropolis. City Community 12(2): $160-168$

Manley L E (2014) Do you live on Spruce Street or are you just straight?: the boundaries of Philadelphia's Gayborhood and the production of queer identities. MA thesis, City University of New York

Massey D (1995) Places and their pasts. Hist workshop J, 39:182-192. Oxford University Press, Oxford, UK

Midtown Village Merchants' Association (2018) Our History. Available via http://midtownvillagep hilly.org/history.php

Milani T (2014) Sexed signs: queering the scenery. Int J Sociol Lang 228:201-225

Modan GG (2008) Turf wars: discourse, diversity, and the politics of place. Blackwell, Malden, MA

Moriarty SE (2002) The symbiotics of semiotics and visual communication. J Vis Lit 22(1):19-28

Owens E (2019, October 19) There goes the Gayborhood. Philadelphia Magazine. Available via https://www.phillymag.com/news/2019/10/19/gayborhood-midtown-village/

Owens C, Dent M (2017, June 16) Straightwashing: Woody's and how Philly's gay bars are less gay. Billy Penn. Available via https://billypenn.com/2017/06/16/straightwashing-woodys-andhow-phillys-gay-bars-are-less-gay/

Pierce J, Martin DG, Murphy JT (2011) Relational place-making: the networked politics of place. Trans Inst Br Geogr 36(1):54-70

Pink S (2008) An urban tour: the sensory sociality of ethnographic place-making. Ethnography 9(2):175-196

Scollon R, Scollon SW (2003) Discourses in place. Routledge, London

Shaw J (2019, October 13) As Philly celebrates outfest, crowd wonders: who repainted rainbow crosswalk? The Philadelphia Inquirer. Available via https://www.inquirer.com/news/philly-out fest-celebration-rainbow-crosswalk-20191013.html

Shohamy E, ben Rafael E, Barni M (2010) Linguistic landscape in the city. Multilingual Matters, Clevedon, UK

Skiba B (2014, February 14) The roots of the Gayborhood, the eve of a milestone. Hidden City. Available via https://hiddencityphila.org/2014/02/the-roots-of-the-gayborhood-the-eve-of-a-mil estone/

Spikol L (2012, February 24) Don't mess with the Gayborhood. Philadelphia Magazine. Available via https://www.phillymag.com/news/2012/02/24/gayborhood-midtown-village-name-change/

Stein M (2004) City of Sisterly and Brotherly loves: lesbian and gay Philadelphia, 1945-1972. Temple University Press, Philadelphia, PA

Trinch S, Snajdr E (2017) What the signs say: Gentrification and the disappearance of capitalism without distinction in Brooklyn. J Sociolings 21(1):64-89

Valentine G (2002) Queer bodies and the production of space. In: Richardson D, Seidman S (eds) Handbook of lesbian and gay studies. Sage, London, pp 145-160 
Wienke C, Whaley RB, Braatz, R (2021) Are "Gay" and "Queer-friendly" Neighborhoods healthy? Assessing how areas with high densities of same-sex couples impact the mental health of sexual minority and majority young adults. In: Bitterman A, Hess DB (eds) The life and afterlife of gay neighborhoods: renaissance and resurgence. Springer, Dordrecht, Netherlands, pp 183-202

Greg Niedt is an Instructor in the Liberal Arts department at the Pennsylvania Academy of the Fine Arts (PAFA) in Philadelphia. Greg's research focuses on how discourses of cultural, gender, and linguistic diversity are represented in the urban landscape and interpreted by its occupants.

Open Access This chapter is licensed under the terms of the Creative Commons Attribution 4.0 International License (http://creativecommons.org/licenses/by/4.0/), which permits use, sharing, adaptation, distribution and reproduction in any medium or format, as long as you give appropriate credit to the original author(s) and the source, provide a link to the Creative Commons license and indicate if changes were made.

The images or other third party material in this chapter are included in the chapter's Creative Commons license, unless indicated otherwise in a credit line to the material. If material is not included in the chapter's Creative Commons license and your intended use is not permitted by statutory regulation or exceeds the permitted use, you will need to obtain permission directly from the copyright holder. 